\title{
Using digital technologies to create equal opportunities in higher education in the Russian Federation: COVID-2019 lessons
}

\author{
Anna Kozyreva*, and Ruslan Nadtoka \\ Lomonosov Moscow State University, Leninskie gory,1,119991Moscow, Russia
}

\begin{abstract}
The article examines the experience of higher education educational organizations of the Russian Federation in the development and implementation of digital tools and services to form equal access to educational content. The Anti-Crisis Measures adopted by the Ministry of Science and Higher Education of the Russian Federation to regulate the higher education sector are being evaluated to ensure that education is accessible and that the learning process is stopped during the COVID-19 pandemic.Over the past few months, studies in higher education on the quality of digital solutions used and their adequacy during the spread of the pandemic of the new COVID-2019 coronavirus infection and the transition mainly to remote forms of educational services show a low degree of readiness to provide equal access to education and reflect the risks of social conflict. It is important to ensure the digital readiness of higher education organizations to provide quality educational services through the introduction of advanced domestic programs and technologies, including those with elements of artificial intelligence; training of teachers and the administrative staff of educational institutions. Particular attention is paid to ensuring access to education in the subjects of the Russian Federation, where students and entrants face difficulties in remotely studying national languages and national culture. The study proposes to consider, among other things, support for the creation and implementation of online educational courses in the languages of national minorities, the expansion of e-library services containing unique cultural and language content, taking into account the specifics of the region's learners.
\end{abstract}

\section{Introduction}

With the active development of globalization[1] and the proliferation of information and communication technologies, the higher education sector has undergone significant changes in recent years. The cost of educational technologies was falling, mobile devices and

${ }^{*}$ Corresponding authors: ORCID ID : 0000-0003-3427-7270 
technologies became more accessible, allowing more citizens to use online educational products and services. According to international research in the first quarter of 2020, there were more than 5.19 billion mobile phone users in the world, in one calendar year the increase was 124 million people (2.4\%)[2]. In the Russian Federation, the number of Internet users in the period prior to the spread of the new coronavirus infection was estimated at between 110 million and 118 million. This means that $79 \%-81 \%$ of the country's citizens [2,3] - use the Internet. Relatively high participation of the population in the information and communication environment (on average, Russian citizens spend 7 hours 17 minutes on the Internet, for comparison - in Japan 4 hours and 22 minutes) raises questions of readiness not only of the state, but also of existing social and industry institutions, to ensure equality of opportunities and accessibility of education throughout the country. The quintessence of the process of ensuring equality of opportunity in the context of mass informatization of the educational process and the transition to digital transformation of the education sector are several factors and, accordingly, states that need to be defined at the current, transitional stage of the higher education system.

First of all, the overall readiness of universities for digital transformation is an important issue: the availability of appropriate infrastructure, access to the Internet in all the facilities necessary to ensure the educational process, namely, in educational laboratories, campuses and dormitories. Secondly, the need to provide software and an informative portal, as well as the functionality of personal classrooms of students. The priority issue remains the creation of accessible, understandable online courses, adaptive educational lectures in face-to-face and remote modes using interactive boards, virtual and augmented reality technology, video communication systems, with the possibility of receiving feedback from students in different formats.It is also necessary to note the distinctive features of the current Russian reality in the field of higher education.

1. The number of young people belonging to the generation is increasing [4]. According to Federal State Statistic Service (Rosstat), the number of young people between the ages of 0 and 24 in 2019 was 40 million [5]. According to the hypothesis, with the increase in the number of young "zoomers" and the increasing age of faculty of educational organizations in the coming years there will be a significant gap in digital skills and competences, which can significantly worsen the quality and speed of education, and lead in turn to psychological burnout of teachers. Such an outcome could have a direct impact on the quality and accessibility of education in individual regions of the country. A study in 2018 confirmed such concerns. According to the NAFI study, one in three teachers claims that a significant proportion of their colleagues at school and university (40 to 100\%) uses digital technology insecurely. According to NAFI, the highest rates of digital literacy are shown by people under 44 years (59-61\%)[6]. Russians over the age of 55 have the lowest digital literacy rates. In addition, it should be noted that according to the data of the unified form of statistical monitoring of the Ministry of Science and Higher Education of the Russian Federation, VPO1 for 2019, about half of the staff belonging to the faculty are over 50 years old.

2.The Russian Federation is a multi-ethnic state, with more than 190 ethnic groups with their own cultural, linguistic and domestic characteristics according to the 2010 census[7]. Although 193 people were allocated in the preparation of the 2010 Census data, 318 peoples have already been listed in the final drafting of the census data, which is mainly due to the allocation of peoples from foreign countries. It is important to note that the change in the list of peoples between the last censuses of 2002 and 2010 is not as significant as in 1989-2002, but this change did not dictate the renewal of the internal educational policy in the direction of actively expanding the list of educational materials, especially for representatives of small peoples. In the context of digital transformation in education, the imperative task towards universal equality in education is to provide a step-by-step opportunity for young people who 
identify with diverse ethnic groups to knowledge and information not only in the state but also in the national language.

3.The transfer of students to remote forms of education, social isolation and increased requirements for the technological provision of the educational process, including with international students in the conditions of closing borders, has become a challenge for the entire field of higher education. In the new sanitary and epidemiological reality, individual student support plays an important role, the formation of a favorable social and psychological climate for working in the video conferencing system with a variety of tools (e.g. zoom, Skype, TrueConf), and providing students with a minimum set of devices and services to ensure the effectiveness of self-learning (Figure 2).

\section{Materials and Methods}

The study includes two areas of study of the processes and events associated with the availability of higher education in an unfavorable sanitary and epidemiological situation. It should be noted that the subject matter of the study is purposefully limited to the field of higher education and higher education organizations, ensuring the realization of the rights and opportunities of students (students, entrants, graduate students), as the remaining levels of education faced a number of other problems.

The first direction is the practical monitoring of the accessibility of education to ethnically heterogeneous groups in the subjects of the Russian Federation and national minorities in particular, for this purpose was conducted a sociological study in the regions with a list of questions on the availability, convenience and quality of training in a remote form, under the conditions of COVID-19. The survey was conducted from September 9 to September 16, 2020 and was carried out through student councils and volunteer associations. A total of 760 students from 1-4 courses of higher education organizations took part in the survey. At the second level, the study is presented by the Ministry of Science and Higher Education of the Russian Federation in conjunction with research organizations and with the help of the monitoring system "Information and Analytical System "Monitoring" the collection of data on the readiness of information and telecommunications infrastructure in the educational organization of higher education in March- May 2020 in several categories: the use of learning management system, Internet connection and readiness to engage students through video conferencing.In addition, in order to verify the availability of online courses in the languages of ethnic groups living in the Russian Federation, the work of the portal, the onewindow aggregator "Modern Digital Education Environment in the Russian Federation" [8], was analyzed, which is in the experimental phase and was open to all students during the COVID-19 period, with the opportunity to take free courses and the results of which were read out by higher education organizations. For this purpose, the official portal of the Ministry of Science and Higher Education of the Russian Federation has described the procedure for applying for access to online courses by teachers in case the educational organization has the necessary capacity to organize quality education[9].

The problem of access of ethnic groups to equal education in remote forms of education in the Russian Federation deserves special attention. At the same time, ethnic groups in this study refer to groups consisting of representatives of peoples living in the territory of the Russian Federation in national republics, autonomous districts, including whose names reflect the ethnic name. It is important to note that many ethnic groups live outside their territorial formations, spread out as a result of many socio-economic, cultural and political factors throughout the Russian Federation. Ethnopolitical issues are most fully represented by studies of the Institute of Anthropology and Ethnology of the Russian Academy of Sciences (including in the works of V.A. Tishkov, Y.L. Diakov, etc.) [10,11]. To date, the issue of access to education for ethnic groups has been resolved only at the level of general 
education. In 2018, the President signed the Federal Law on Amending Articles 11 and 14 of the Federal Education Act in the Russian Federation. According to the new version of the federal law, "the free choice of the language of education studied by the native language from among the languages of the peoples of the Russian Federation, including Russian as the native language, the state languages of the republics of the Russian Federation is carried out on the application of parents (legal representatives) of minors to receive (translation) for education programs of pre-school education, which have state accreditation programs of primary general and basic general education."[12,13,].At the same time, questions remain about the readiness of higher education organizations not only to formally provide the opportunity to assimilate individual materials and disciplines in their native languages, but also to technically ensure the transition to educational content for students, including in emergencies similar to the COVID-19 pandemic, through the introduction of digital technologies.

In terms of digital technologies in education, it should be noted that these are technologies that are more accessible to students in the educational process, and thus ensure equal access, regardless of social or other factors. Technology should be human-oriented and aimed at creating a new educational material in accordance with the needs of the economy and society, as well as in the interests of harmonious development of the individual, revealing its creative potential. Therefore, we are talking about the transformation of lecture material into a video flow series, the creation of digital texts and electronic tests. International publications and studies on the use of digital technologies show that their role in the process of assimilation of material, efficiency in terms of time and perception of knowledge, motivation to learn and concentration is essential [14].A special place is occupied by the development of online courses and attempts to give an answer to the question of which courses are really considered taking place in an online format. According to experts, online courses, for all the variety of terminology apparatus (in international usage use such terms as e-learning, digital learning, online learning, distance learning) include courses where the share of content provided in favor of the student is more than $70-80 \%$ [15]. With regard to the development of digital technologies, it should be noted that a particular problem is the lack of a single terminology apparatus. In the Russian Federation, strategic documents, namely the national program "Digital Economy of the Russian Federation" and the Information Society Development Strategy for 2017-2030, have been approved to promptly manage the digital transformation of the economy, together with the growing expectations of society in 2017.[16]. These include: regulation, personnel and education, the formation of research competencies and technical backlogs, information infrastructure and information security, where some digital technologies have been identified and projects have been laid to create breakthrough innovative solutions in education, as well as to improve digital literacy, quality and accessibility of education. In addition to the development of digital literacy at the national level, all the main issues of accessibility of education, including electronically defined in the updated Federal Law of 29.12.2012 N 273 Federal Law "About the Education in the Russian Federation" [12]. Thus, Article 16 of paragraph 2 of the Federal Law states that "educational organizations have the right to use e-learning, remote educational technologies in the implementation of educational programs..."[12].In parallel with the improvement of the Federal Legislation, national projects of the Russian Federation have also been supplemented. In 2018, a federal digital project was added to the updated and refined national program "Digital Economy in the Russian Federation" which listed the priority "end-to-end" digital technologies: big data; New manufacturing technologies Industrial Internet; Artificial intelligence Wireless technology Robotics and sensor components quantum technology; Distributed registry systems virtual and augmented reality technology [17].

\section{Results and Discussion}


According to the studies carried out in conjunction with the Ministry of Science and Higher Education of the Russian Federation, the following results were obtained among higher education organizations between March and May 2020. Of the 480 universities, more than $80 \%$ used the Moodle solution as their primary learning management system. Given that the Moodle platform has a high performance in terms of functionality and requires high user training, the question arises about the quality and availability of appropriate skills and competencies on the part, both faculty and students to work with the system.

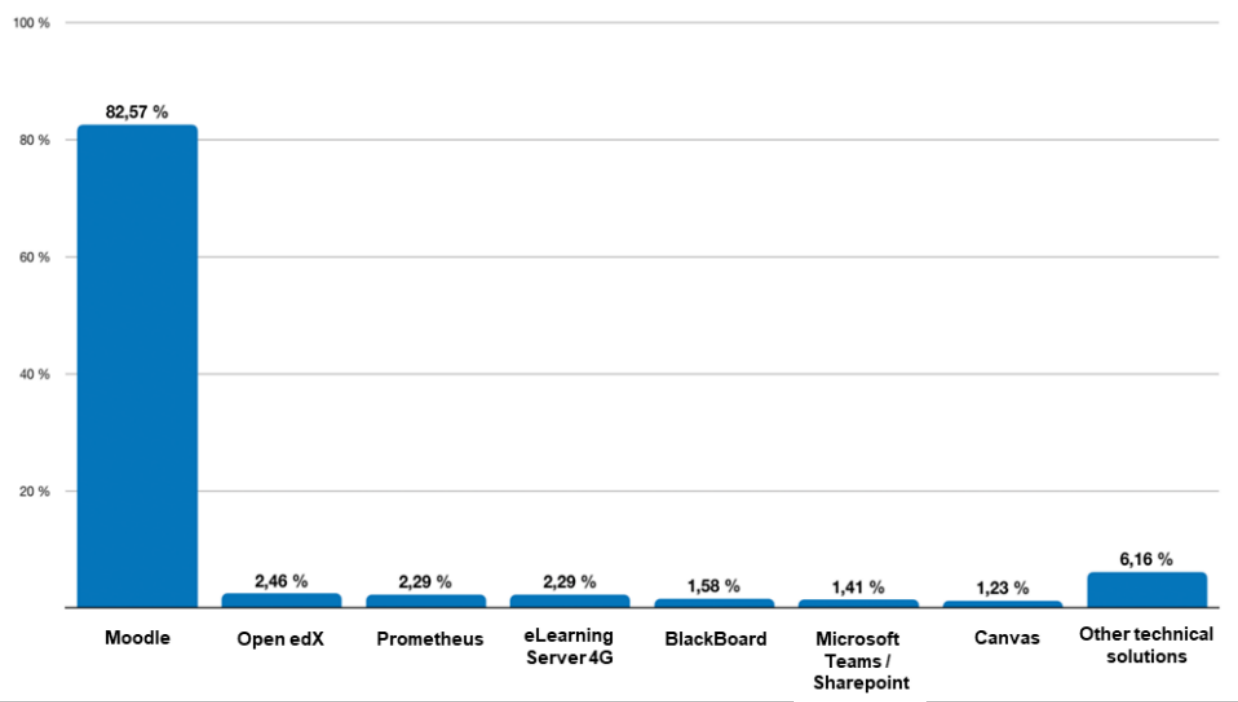

Fig.1. Name of the main LMS platforms used for educational purposes by universities (in percentage)

At the same time, represented by 500 universities in about $50 \%$ of cases, all participants in the educational process use LMS platforms and only $25 \%$ of cases this indicator is minimal. In addition, 47 per cent of universities have a face-to-face course with more than 80 per cent of LMS, while 23 per cent of universities have a share of LMS course below 30 per cent. In conducting the analysis of data, it is important to take into account the results of the sociological study, so to the question "Are you satisfied with the process of training in a remote mode?" $23.6 \%$ of respondents said that they are completely satisfied, $27 \%$ that are satisfied only partially, the rest took the results of distance learning, including using LMS platforms negatively. To the question "Could the university offer you a convenient format of distance learning in the spring semester of the school year?" only $51 \%$ of students answered in the affirmative.

It should be noted that access to the Internet is the cornerstone of equal access to education in the context of digital reformation and the global COVID-19 pandemic. According to a study of 580 higher education organizations, only 3 organizations had no Internet connection as of March 2020. At the same time, the potential for small growth is demonstrated by the majority of participants of most universities. In addition, most universities $(82.1 \%)$ have the technological ability to increase the bandwidth of the communication channel to increase the speed of the connection, in the event of an increase in the load in a remote format.

Table 1. Information on the technological capabilities of universities with an Internet connection

\begin{tabular}{|l||l||l||}
\hline & & The extent to which channels are downloaded \\
\hline
\end{tabular}




\begin{tabular}{|c|c|c|c|c|c|c|c|c|}
\hline \multirow{2}{*}{$\begin{array}{l}\begin{array}{c}\text { Internetacces } \\
\text { schannelperf } \\
\text { ormance }\end{array} \\
\begin{array}{l}\text { Do not have } \\
\text { an Internet } \\
\text { connection }\end{array}\end{array}$} & \multirow{2}{*}{$\begin{array}{c}\begin{array}{c}\text { Numberof } \\
\text { universiti } \\
\text { es }\end{array} \\
3\end{array}$} & \multirow{2}{*}{$\begin{array}{c}\begin{array}{c}\text { Shareofu } \\
\text { niversitie } \\
\text { s }\end{array} \\
0,52 \%\end{array}$} & \multicolumn{2}{|c|}{$\begin{array}{c}\text { Low } \\
(\text { less 30\%) }\end{array}$} & \multicolumn{2}{|c|}{$\begin{array}{c}\text { Middle } \\
(\mathbf{3 0 - 7 0 \% )}\end{array}$} & \multicolumn{2}{|c|}{$\begin{array}{c}\text { High } \\
(\text { over } 70 \%)\end{array}$} \\
\hline & & & - & - & - & - & - & - \\
\hline $\begin{array}{l}\text { Low } \\
\text { Lessthan } 50 \\
\text { Mbps }\end{array}$ & 92 & $15,86 \%$ & 28 & $\begin{array}{c}30,43 \\
\%\end{array}$ & 42 & $45,65 \%$ & 18 & $19,57 \%$ \\
\hline $\begin{array}{l}\text { Below the } \\
\text { middle } \\
\text { From } 50 \text { to } \\
100 \mathrm{Mbit} / \mathrm{s}\end{array}$ & 136 & $23,45 \%$ & 54 & $\begin{array}{c}39,71 \\
\%\end{array}$ & 53 & $38,97 \%$ & 25 & $18,38 \%$ \\
\hline $\begin{array}{l}\text { Middle } \\
\text { From } 100 \text { to } \\
500 \mathrm{Mbit} / \mathrm{s}\end{array}$ & 208 & $35,86 \%$ & 76 & $\begin{array}{c}36,54 \\
\%\end{array}$ & 106 & $50,96 \%$ & 26 & $12,50 \%$ \\
\hline $\begin{array}{l}\text { Above the } \\
\text { middle } \\
\text { From } 500 \\
\text { Mbit to } 1 \\
\text { Gbit/sec }\end{array}$ & 77 & $13,28 \%$ & 24 & $\begin{array}{c}31,17 \\
\%\end{array}$ & 47 & $61,04 \%$ & 6 & $7,79 \%$ \\
\hline $\begin{array}{l}\text { High } \\
\text { More than } 1 \\
\text { Gbit/s } \\
\end{array}$ & 64 & $11,03 \%$ & 31 & $\begin{array}{c}48,44 \\
\%\end{array}$ & 27 & $42,19 \%$ & 6 & $9,38 \%$ \\
\hline Total & 580 & & 213 & $\begin{array}{c}36,72 \\
\%\end{array}$ & 275 & $47,41 \%$ & 81 & $13,97 \%$ \\
\hline
\end{tabular}

In order to organize training and equal access to online lectures, higher education organizations had to connect video conferencing systems (VKS). As of May-June 2020, it was found that $15 \%$ of the higher education organizations surveyed by higher education universities (among those who provided the data) lacked their own software to organize conferences and webinars, as well as to ensure that students are involved in their full participation in the educational process (Table 2).

An additional problem in terms of the quality of learning through webinars was the use of solutions that did not allow for the same involvement of more than 50 participants (in the case of the transfer of lecture material), which could have led to a restriction on the applicant's right to receive the material.

Table 2. The results of the analysis of the technical means to ensure the educational process of universities

\begin{tabular}{|l|c|c|}
\hline \multicolumn{1}{|c||}{$\begin{array}{c}\text { Study of 580 universities of the Russian } \\
\text { Federation }\end{array}$} & Numberofuniversities & Shareofuniversities \\
\hline $\begin{array}{l}\text { The university does not have VKS and webinar } \\
\text { services } \\
\text { (bothinternalandexternal) }\end{array}$ & 86 & $15,0 \%$ \\
\hline $\begin{array}{l}\text { The university has a subscription to the cloud } \\
\text { service VKS and webinars }\end{array}$ & 413 & $71,9 \%$ \\
\hline $\begin{array}{l}\text { The presence of VKS and webinars deployed on } \\
\text { university resources }\end{array}$ & 321 & $55,9 \%$ \\
\hline
\end{tabular}




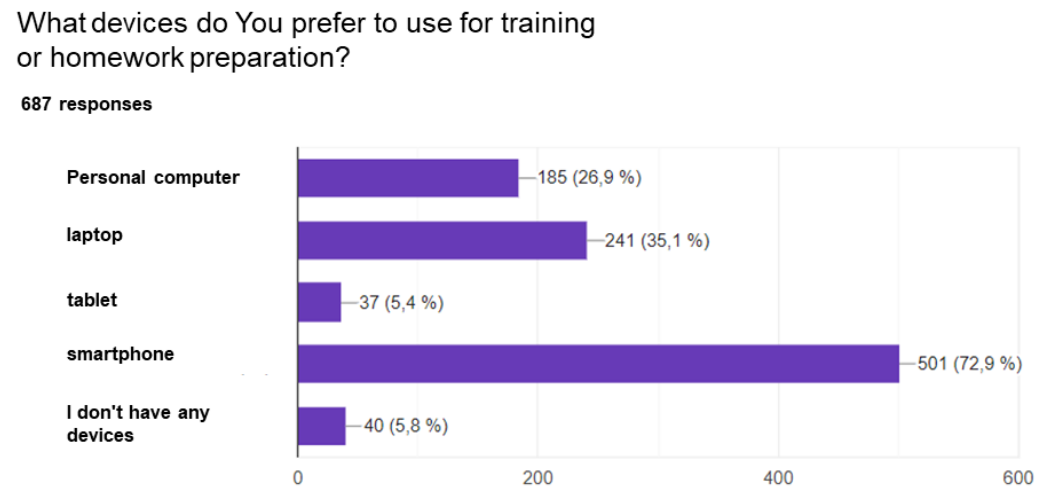

Fig.2.The result of an analysis of the technical security of students

It is also important to note the role of digital personal devices in the learning process. Of the 687 respondents in the multiple-response version, the vast majority $(72.9 \%)$ said they would like to have a good answer. uses a smartphone. This leads to the conclusion that students prefer to listen to the information received without its subsequent fixation in electronic format, give the advantage also to visual contact with the study of materials. This raises the question of the effectiveness of training using only a smartphone, as the functionality of this type of devices does not allow a full study of online courses, perform tasks and outline the material. (Fig.2)

In addition, the responses of respondents who pointed out the complete absence of any of the devices are interesting. In this case, for $5.8 \%$ of students, from the survey, training in a remote format on educational programs was impossible. This information correlates with the nationwide poll conducted by the Public Opinion Foundation in May 2020 [18]. According to the survey, one in five Russians has never used the Internet, which is $22 \%$ of the total number of respondents. At the same time, the answers "never used the Internet" and "used last six months ago" were given by $1 \%$ of respondents under the age of 24 . It should be understood that the reasons for such answers may be the subjective desire of respondents not to access the Internet in principle [20].

In general, it is possible to track the quality of the content offered and the ability of students to connect to their personal offices for online training and the number of applications to the created at the Ministry of Science and Higher Education of the Russian Federation Situation Center, which has been operating since March 16, 2020. Between 17 March and 31 August 2020, 1,052 applications were received, 1/3 of which were related to the organization of the learning process. This was how 371 requests were received and processed, of which 2 related to individual curriculums, 19 to intermediate assessment of students, 51 to final certification and technical readiness, rules for the use of pro-factoring, 5 to eliminate debt from students in distance learning, 30 to practice organizations in senior and laboratory replacement courses, 51 for distance learning. Only 7 requests were related to the practice of using online courses, while more questions were raised by university staff on distance learning (230 questions). The relatively small number of requests during such a long period of self-isolation in the Russian Federation indicates a low awareness of citizens (except for the leadership of the educational institutions themselves) about the possibilities of distance learning and the existence of anti-crisis measures supported by the Ministry of Science and Higher Education of the Russian Federation, as well as the presence of other more pressing problems facing students and residents of the regions (unemployment, social exclusion, a 
general decline in living standards, etc.). At the same time, it should be noted that the issues of information security of personal data require further study.

In this regard, given the multi-ethnic nature of relations in the Russian Federation and equal access to educational opportunities, including through distance learning systems, it is necessary determining the openness of online courses to national minorities and compact peoples in the subjects of the Russian Federation. Analysis of youth activity in the regions of the country on social networks and the portal-aggregator of the resource "Modern Digital Environment in the Russian Federation" (SOCS in Russia) shows three main challenges in achieving the goal number 4 in the field of sustainable development "Ensuring inclusive and equitable quality education and promoting the possibility of lifelong learning for all". First of all, it is a shortage of educational programs and high-quality online courses. Thus, only the national course of 1,795 courses[19] was found on the portal "SOCS in Russia", namely the basic course of Chuvash language.

\section{Conclusion}

1. During the COVID-19 pandemic, the higher education system faced serious challenges. Preventive measures to combat coronavirus, such as the transfer of students to distance learning, working with foreigners and closing borders, have become a serious challenge for many higher education and public education organizations.

2. Thanks to the prepared changes over the past three years in the form of amendments to the Federal Education Act in the Russian Federation, the adoption of strategic documents national projects in the field of digital economy, science and education, as well as a timely response to the stress test of the entire field of higher education by the Ministry of Science and Higher Education of the Russian Federation, educational organizations of higher education, managed to conduct the educational process in the spring semester of 2020 without a significant disruption in accordance with the training schedule. Among the anti-crisis measures taken, it is important to separate the successful practices: the creation of a situational center of the Ministry of Science and Higher Education of the Russian Federation, the adoption of a number of minister's recommendations regulating the procedures for transferring to remote forms of education, as well as two and multilateral measures to support higher education organizations in terms of increasing the capacity of communication channels and cloud storage facilities for the successful operation of students' personal classrooms and recording information about learning.

3. Through a balanced transition to distance learning in March and April 2020, the principle of equal access to education was achieved, in line with the Sustainable Development Goals No.4 ,providing inclusive and equitable quality education and promoting lifelong learning opportunities for all" in terms of higher education. At the same time, it must be recognized that there is a technical opportunity to obtain educational content, namely access to the Internet, which is more of a problem of household financial and economic security. Despite the measures taken by the Government of the Russian Federation, wage disparities still persist in some regions, and unemployment has been adjusted as a result of the selfisolation regime. These factors are temporary, but still have a negative impact on the ability to purchase digital equipment for online learning. The coverage of the Internet throughout the Russian Federation, although some higher education organizations have provided equipment for temporary use, it has not been sufficient to meet all the needs of the students.

4. Timely implementation of activities within the framework of the national projects "Education" adopted by the Government of the Russian Federation, "Digital Economy in the Russian Federation" will allow to ensure maximum connection of socially significant objects and educational organizations to the high-speed Internet, as well as to provide significant grants for the preparation of educational online courses for students in various areas of 
training within the existing classification of disciplines. A number of competitions for the development of online courses have already been contested by a competition commission of the Ministry of Science and Higher Education of the Russian Federation in May this year. In addition, the industrial launch of the single window aggregator portal "Modern digital educational environment in the Russian Federation at the end of 2020 and the preparation of the project of an individual platform of continuing education will provide access to continuous education and quality online courses with the personal office of the student and the opportunity to re-start educational programs, including in the case of transition from one educational organization of higher education to another.

5. Comprehensive measures to upgrade the infrastructure base, as well as the introduction of new platforms and services provided by national projects, will ensure equal access to higher education from anywhere to national minorities and ethnic groups, both within and outside the country.

6. Taking into account the lack of online courses in national languages and the lack of diversity of nationally specific training programs, it is necessary to continue to work on the development of a new methodology to strengthen the intercultural interaction of students at the university. It is also important to ensure that specialized online courses and programs aimed at the peoples of the Russian Federation are established, that digital literacy is improved in the field and that students and teachers from remote regions and territories are predominantly traditional fisheries. Such steps would provide ethnic groups with equal opportunities to study in higher education and would ensure a willingness to embrace the values of the culture of the titular ethnic group, without losing their identity and increasing the values of regional culture, which is seen as an integral part of personal development.

In general, it should be noted that the main results of maintaining continuing education in the face of restrictions associated with the spread of COVID-19 is the need to further work on the technological and legal basis for the use of digital technologies in the training needed to create equal opportunities in higher education in the Russian Federation with information security.

\section{References}

1. R. Robertson, SAGEPublicationsltd, 32 (2000)

2. Digital use around the world 2020, Global Report, Wearesocial ltd, https://wearesocial.com/

3. $78 \%$ Russians used the Internet, according to a studyMediascope, https://mediascope.net/

4. G. Beall, 8 Key Differences between Gen $Z$ and Millennials, (2016), https://www.huffingtonpost.com

5. Population size, distribution of population by age group, Rosstat,http://old.gks.ru/

6. NAFI reserch, https://nafi.ru/

7. Ethnic composition of the population of the Russian Federation, Rosstat, https://rosstat.gov.ru/

8. Portal-aggregator «Modern digital educational environment in the Russian Federation»(SCOS in the Russian Federation), http://neorusedu.ru/

9. Official site of the Ministry of Science and Higher Education of the Russian Federation, https://www.minobrnauki.gov.ru/

10. Scientific research in the field of ethnicity, interethnic relations and the history of national politics. Proceedings of the RAS Scientific Council session on complex problems of ethnicity and interethnic relationsu, December 19, 2017, IEARAN (2018) 
11. V.A. Tishkov, Ethnology and politics. Scientific journalism, Moscow: Nauka (2001)

12. Federal Law 29.12.2012 N 273-FL «About the Education in Russian Federation», 31.07.2020

13. Official website of the President of the Russian Federation, http://www.kremlin.ru/

14. Sarah Grand-Clement, Axelle Devaux, Julie Belanger, Catriona Manville, RAND Report: Digital learning Education and skills in the digital age, https://www.rand.org/

15. I.E. Allen, J. Seaman, Babson Survey Research Group, Going the Distance. Online education in the United States, 7(2011)

16. A.A. Kozyreva, Law and state: theory and practice, 12(156), 130 (2017)

17. Ministry of Digital Development, Communications and Mass Media of the Russian Federation, passport of the federal project "Digital Technologies", https://digital.gov.ru/

18. Research by the Public Opinion Foundation: Internet and Online Services, https://fom.ru/

19. Analysis of the courses of the portal-aggregator "Modern digital educational environment in the Russian Federation" (SCOS inRussia), https://online.edu.ru/

20. A.A. Kozyreva, Information wars: socio-ethical, aesthetic, anthropological aspects and countermeasure technologies.Materials of the All-Russian Scientific Conference, 47(2015)

21. L.N. Bokova, Herald of the Russian University of Peoples' Friendship. Series: Legal Sciences, 3, 274(2020) 